\title{
OBTENÇÃO DE BIODIESEL DE GORDURA ABDOMINAL DE FRANGO
}

\author{
M. ZANETTI ${ }^{1}$, J. P. BENDER ${ }^{2}$, C. DALLA ROSA ${ }^{2}$, H. TREICHEL ${ }^{2}$, D. PERON ${ }^{1}$, A. FURIGO \\ $\mathrm{Jr}^{3}$
}

${ }^{1}$ Universidade comunitária da Região de Chapecó - UNOCHAPECO - Chapecó, Departamento de Engenharia Química

${ }^{2}$ Universidade Federal da Fronteira Sul - UFFS - Erechim, Departamento de Engenharia de Alimentos

${ }^{3}$ Universidade Federal de Santa Catarina - UFSC - Florianópolis, Departamento de Engenharia Química e de Alimentos

E-mail para contato: eng.miche@unochapeco.edu.br

\begin{abstract}
RESUMO - No presente trabalho foi realizada a produção de biodiesel com gordura abdominal de frango, a qual é uma matéria-prima de baixo custo, utilizando catálise básica. O efeito das variáveis: relação gordura:etanol, concentração do catalisador e da temperatura na produção de biodiesel foram avaliadas. As condições ótimas para o processamento foram realizadas na proporção de gordura: etanol 1:6, concentração de catalisador $\mathrm{NaOH}$ de $1,75 \%$ e uma temperatura de $50{ }^{\circ} \mathrm{C}$. Em condições ótimas, foi obtida uma conversão em éster de $98,2 \%$, depois de 20 min na presença do catalisador. O biodiesel obtido nessas condições é consistente com os padrões da Agência Nacional do Petróleo (ANP) Resolução 07/2008, relativas às características que foram avaliadas neste estudo densidade, viscosidade e ponto de entupimento do filtro a frio.
\end{abstract}

Palavras chave: Biodiesel, gordura abdominal de frango, catálise básica.

\section{INTRODUÇÃO}

No Brasil, o Programa Nacional de Produção e Uso de Biodiesel (Programa Nacional de Produção e Uso de Biodiesel; PNPB) prevê um programa de substituição de combustíveis envolvendo um aumento progressivo na proporção de biodiesel adicionado ao combustível fóssil. Dentro deste programa, vários tipos de óleos vegetais estão sendo investigados como possíveis materiais de base, de modo a aproveitar o social, econômica e biológica diversidades das diferentes regiões do país [1].

Considera-se biodiesel o combustível obtido de biomassa renovável que possa substituir parcial ou totalmente o óleo diesel de origem fóssil em motores ciclo diesel, automotivos e estacionários. Esta definição é relevante para evitar a discriminação de qualquer rota tecnológica para a obtenção desse combustível de fonte vegetal ou animal, o que permite incluir, além do próprio óleo in natura, o obtido por transesterificação etílica ou metílica, por craqueamento, ou ainda por transformação de gases obtidos de biomassa em líquidos [2]. 
Atualmente, a matéria-prima graxa mais utilizada na produção de biodiesel no Brasil é a soja. A inclusão de outras matérias-primas, oriundas de diferentes culturas nesse setor, é importante e visa diminuir a dependência em uma única oleaginosa, além de poder atribuir características interessantes ao produto e incentivar o desenvolvimento da agricultura familiar [3]. Os subprodutos de frigoríficos e abatedouros animais podem atingir 2 milhões de tonelada de gorduras animais. A utilização da gordura (óleos de frangos, graxa suína e sebo bovino) tem possibilidade de direcionamento para a produção de biodiesel, configurando-se como uma alternativa extremamente promissora [4].

O método mais comum para a produção de biodiesel é por reação de transesterificação. Esta reação pode ser realizada por catálise básica, ácida ou por enzima [5], onde os dois primeiros tipos têm recebido a maior atenção e são o foco deste artigo. Na maioria dos processos de produção de biodiesel em todo o mundo, o álcool utilizado é o metanol [6]. No entanto, o etanol é mais interessante do ponto de vista da sustentabilidade tecnológica, desde que se trata de fontes renováveis, enquanto o metanol é geralmente um derivado do petróleo. Além disso, o etanol é produzido em larga escala no Brasil.

Tem crescido o interesse ao longo dos últimos anos, em investigar as propriedades de novos combustíveis gerados a partir de novas alternativas de matérias primas. Neste contexto, nós investigamos a transesterificação de gordura abdominal de frangos, na presença de etanol, a fim de obter informações sobre os processos industriais alternativos para a produção de biodiesel a partir de rejeitos de agroindústria.

\section{MATERIAIS E MÉTODOS}

A matéria-prima utilizada para a produção de biodiesel foi a gordura abdominal de frangos, cedida pelo Frigorífico de Aves da Brasil Foods de Chapecó. A gordura abdominal de frangos precisa ser primeiramente preparada fazendo a separação da gordura e levando para estufa por $1 \mathrm{~h} \mathrm{a} 100^{\circ} \mathrm{C}$, para a remoção de água residual que possa estar presente. Esta água precisa ser removida para não prejudicar o rendimento da reação de transesterificação.

As amostras de gordura abdominal de frango foram caracterizadas usando os métodos utilizados pela Agência Nacional do Petróleo (ANP) que estabelece os procedimentos para a análise de composição em ácidos graxos, determinação da densidade, densidade relativa e viscosidade cinemática. $\mathrm{O}$ índice de acidez e índice de iodo da gordura foram determinados pela ABNT NBR ISO 14448 e EN 14111, respectivamente [7, 8].

Para a reação de transesterificação da gordura em biodiesel utilizou-se álcool etílico (P.A 99,5\% Nuclear). O catalisador hidróxido de sódio P.A. (VETEC - Química Fina Ltda) foi dissolvido no álcool e depois de sua completa dissolução foi adicionada a gordura. Todos os reagentes foram medidos em balança (TECNAL, modelo Mark 210) e depois agitadas a 40 rpm em agitador (Shaker Bath, modelo DST 01). O biodiesel foi então submetido ao processo de lavagem com uma solução de $100 \mathrm{~g}$ de água destilada aquecida até $90{ }^{\circ} \mathrm{C}$ e adicionado 4 gotas de ácido clorídrico (VETEC Química Fina Ltda) para remover as impurezas que ficam na fase éster, como sabões, traços de catalisador, traços de álcool e glicerol livre. Em seguida, 
os traços de umidade e de álcool foram eliminados através de secagem com sulfato de sódio anidro P.A. (VETEC Química Fina Ltda). Após estas etapas determinou-se a concentração de éster no biodiesel.

Para as análises cromatográficas foram utilizados padrões do etil éster do ácido nervônico (C24:1) e o etil éster do ácido mirístico (C14) e como padrão interno foi adotado o heptadecanoato de etila (C17:0), todos de procedência Sigma-Aldrich. Para o preparo das soluções foi utilizado como solvente n-heptano marca Merck $(99,9 \%)$, cuja pureza segue a norma Europeia EN 14103. Após coletado, uma alíquota de $0,25 \mathrm{~g}$ da amostra foi transferida para um balão volumétrico de $10 \mathrm{~mL}$. Sobre esta amostra foi adicionado $5 \mathrm{~mL}$ de solução de padrão interno de heptadecanoato de etila em concentração de $10 \mathrm{mg} / \mathrm{mL}$ com auxílio de uma pipeta graduada. A amostra foi agitada e uma alíquota (cerca de $1 \mathrm{~mL}$ ) transferida para os vials dando sequência a análise cromatográfica. A solução foi então injetada em triplicata em um cromatógrafo gasoso com detector de ionização de chama (CG/FID Shimadzu modelo 2010) equipado com uma coluna capilar apolar modelo RT-WAX (contendo polietileno glicol na fase estacionária), de $30 \mathrm{~m}$ de comprimento, diâmetro interno de $0,32 \mathrm{~mm}$ e com as seguintes condições cromatográficas: temperatura inicial da coluna de $150{ }^{\circ} \mathrm{C}$, permanecendo por 1 min nesta condição, taxa de aquecimento de $10{ }^{\circ} \mathrm{C} / \mathrm{min}$ até atingir a temperatura final da coluna de $250{ }^{\circ} \mathrm{C}$, permanecendo por 1 minuto nesta condição. A temperatura do injetor e do detector foram estabelecidas em $250{ }^{\circ} \mathrm{C}$. A quantidade da solução de amostra injetada foi de 1 $\mu \mathrm{L}$.

\section{RESULTADOS E DISCUSSÕES}

Foram determinados os valores da massa específica, viscosidade cinemática, índice de acidez e índice de iodo da matéria-prima gordura abdominal de frango para posterior comparação com os resultados do produto biodiesel, os quais foram apresentados na Tabela 1.

Os valores da massa específica e viscosidade cinemática a $40^{\circ} \mathrm{C}$ determinados para a gordura abdominal de frangos encontram-se dentro de valores padrões encontrados na literatura. Estes valores ficaram próximos aos encontrados no estudo de Ramalho (2008) [9], para produção de biodiesel a partir de gordura de frangos em condições similares de reação, cujos valores obtidos foram $907 \mathrm{~kg} \cdot \mathrm{m}^{-3}$ e para a viscosidade de $36,00 \mathrm{~mm}^{2} \cdot \mathrm{s}^{-1}$.

Tabela 1- Propriedades da gordura abdominal de frangos

\begin{tabular}{ccc}
\hline Propriedades & Unidades & Resultados Experimentais \\
\hline Massa específica a $20^{\circ} \mathrm{C}$ & $\mathrm{kg} / \mathrm{m}^{3}$ & 915,7 \\
Viscosidade a $40^{\circ} \mathrm{C}$ & $\mathrm{mm}^{2} / \mathrm{s}$ & 36,85 \\
Índice de acidez & $\mathrm{mg} \mathrm{KOH} / \mathrm{g}$ de amostra & 0,04 \\
Índice de Iodo & $\mathrm{g}$ de iodo/g de amostra & 85 \\
\hline
\end{tabular}


As amostras apresentaram um resultado de índice de acidez adequado, com baixa presença de ácidos graxos livres indicando que a matéria-prima pode ser utilizada para a produção do biodiesel. $\mathrm{O}$ valor $0,04 \mathrm{mg} \mathrm{KOH} / \mathrm{g}$ pode ser considerado baixo, sendo que a grande parte das matérias-primas apresentadas na literatura para a produção de biodiesel apresentam valores mais elevados dos que os encontrados neste estudo. Cunha (2008) [11] encontrou, para amostras de matérias-primas de gordura de frango, valores para índice de acidez de 0,521 mg KOH/g. Para sebo bovino encontrou valores de 0,627 mg KOH/g.

O índice de iodo, encontrado para a gordura abdominal de frangos, também atende o estabelecido na norma europeia, que determina valor máximo de 120 (g de iodo/100g), sendo que o valor encontrado nesta investigação (de $85 \mathrm{~g}$ de iodo/100 g) fica dentro da faixa determinada. A legislação brasileira não determina padrão para esta análise, mas sim, sugere tomar nota.

Na Tabela 2 é apresentada a matriz do planejamento fatorial completo com as respostas correspondentes em termos de concentração de éster. Um dos parâmetros mais importantes é o rendimento do éster, pois este tem um efeito direto no custo de biodiesel [10]. Os resultados mostram que as maiores conversão em éster $(98,2 ; 97,9$ e $95,6 \mathrm{~g} / \mathrm{g} \%)$ foram obtidos em condições de ponto central $\left(50^{\circ} \mathrm{C}, 1,7 \%\right.$ de concentração de catalisador e $1: 6 \mathrm{~g} / \mathrm{g}$ de gordura por massa de etanol).

Tabela 2 - Efeito da Concentração de catalisador, temperatura e razão mássica etanol:gordura na concentração de éster no biodiesel

\begin{tabular}{lllll}
\hline Corrida & $\begin{array}{c}\text { Conc. Catalisador } \\
\mathbf{[ g / g , \% ]}\end{array}$ & $\begin{array}{c}\text { Temperatura } \\
{\left[{ }^{\circ} \mathbf{C}\right]}\end{array}$ & $\begin{array}{c}\text { Razão mássica } \\
\text { gordura:etanol [g/g] }\end{array}$ & $\begin{array}{c}\text { Concentração de } \\
\text { Éster [g/g \%] }\end{array}$ \\
\hline 1 & $-1(1,25 \%)$ & $-1(25)$ & $-1(1: 3)$ & 72,8 \\
2 & $1(2,25 \%)$ & $-1(25)$ & $-1(1: 3)$ & 81,9 \\
3 & $-1(1,25 \%)$ & $1(75)$ & $-1(1: 3)$ & 74,1 \\
4 & $1(2,25 \%)$ & $1(75)$ & $-1(1: 3)$ & 67,4 \\
5 & $-1(1,25 \%)$ & $-1(25)$ & $1(1: 9)$ & 67,7 \\
6 & $1(2,25 \%)$ & $-1(25)$ & $1(1: 9)$ & 69,9 \\
7 & $-1(1,25 \%)$ & $1(75)$ & $1(1: 9)$ & 73,5 \\
8 & $1(2,25 \%)$ & $1(75)$ & $1(1: 9)$ & 79,1 \\
9 & $0(1,75 \%)$ & $0(50)$ & $0(1: 6)$ & 97,9 \\
10 & $0(1,75 \%)$ & $0(50)$ & $0(1: 6)$ & 98,2 \\
11 & $0(1,75 \%)$ & $0(50)$ & $0(1: 6)$ & 95,6 \\
12 & $-1.68(0,91 \%)$ & $0(50)$ & $0(1: 6)$ & 71,1 \\
13 & $+1.68(2,59 \%)$ & $0(50)$ & $0(1: 6)$ & 74,3 \\
14 & $0(1,75 \%)$ & $-1.68(8)$ & $0(1: 6)$ & 95,9 \\
15 & $0(1,75 \%)$ & $+1.68(92)$ & $0(1: 6)$ & 59,0 \\
16 & $0(1,75 \%)$ & $0(50)$ & $-1.68(1: 1)$ & 65,7 \\
17 & $0(1,75 \%)$ & $0(50)$ & $+1.68(1: 11)$ & \\
\hline
\end{tabular}

Através da análise estatística verificou-se que a relação mássica gordura/álcool, a concentração de catalisador e a temperatura apresentam efeito estatisticamente significativo na faixa estudada, nenhum parâmetro foi então retirado do modelo. Com isso foi possível 
obter um modelo empírico para a concentração de éster no biodiesel em função das três variáveis citadas.

A partir da superfície de resposta, percebe-se que o processo está otimizado, uma vez que o máximo de conversão encontra-se em torno do ponto central. A utilização da metodologia de superfície de resposta possibilitou a pesquisa de duas variáveis simultaneamente.

Na Figura 1, pode-se observar que as condições boas para a conversão em ésteres etílicos encontra-se em uma faixa de concentração de catalisador de $1,70 \%$ a 2,20\% de $\mathrm{NaOH}$ e uma faixa de temperatura de 40 a $70{ }^{\circ} \mathrm{C}$. Através desta análise, fica evidente que extremos de temperatura levam a uma diminuição na conversão, pois em baixas temperaturas a gordura abdominal de frango está em estado sólido (Ponto de fusão da gordura abdominal é de $31^{\circ} \mathrm{C}^{1}$ ) o que dificulta a reação. Concentrações elevadas de hidróxido de sódio influenciam a formação de sais de ácidos graxos (sabão), dificultando assim o processo de purificação e ocasionando perda do produto, assim como concentrações muito baixas de catalisador são insuficientes para que a reação ocorra no tempo pré-estabelecido.

Bhatti et al. (2008) [12] encontraram em seu trabalho de produção de biodiesel utilizando gordura de frangos via catálise básica conversões de $88,14 \%$, para temperaturas acima de $40{ }^{\circ} \mathrm{C}$, utilizando uma concentração de catalisador de $1,5 \%$ em massa.

Figura 1 - Superfície de resposta para a concentração de éster no biodiesel em função da concentração do catalisador e da temperatura da reação para razão mássica de gordura/álcool.
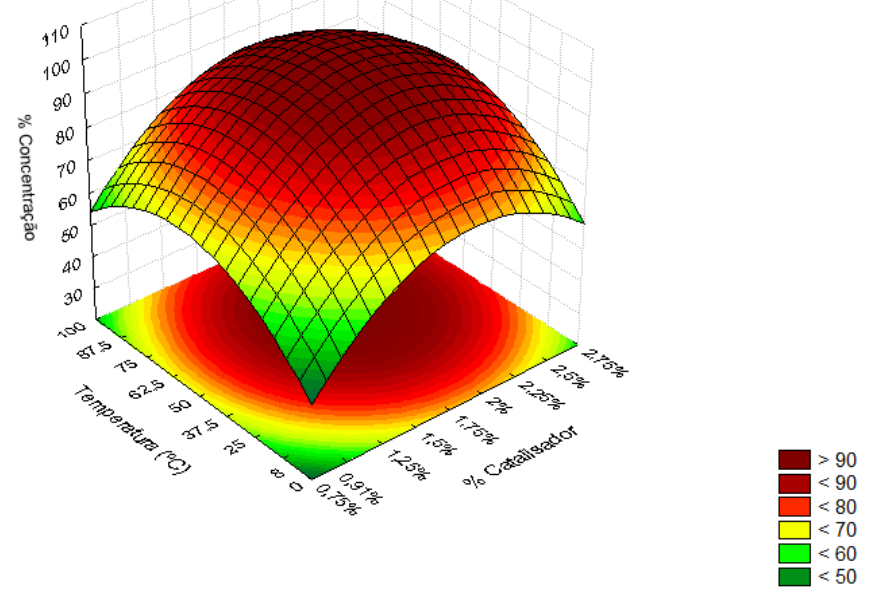

A segunda análise das melhores faixas de conversão de ésteres foi comparando as variáveis razão gordura/álcool e a concentração de catalisador, para a temperatura do ponto central de $50{ }^{\circ} \mathrm{C}$, a qual nos fornece a Figura 2.

\footnotetext{
${ }^{1}$ Valor do ponto de fusão para a gordura abdominal obtido por Ming, C. C.(2001).
} 
Quando avalia-se o efeito da relação gordura/álcool percebe-se que também tem-se uma faixa de ótimo onde obtivemos as conversões acima de $96,5 \%$ preconizado na legislação que está entre 1:5 e 1:7, para concentrações de catalisador de 1,9\% a 2,10\%. Estes valores também foram encontrados por Cunha et al. (2012) [13], que encontraram conversões de $83,5 \%$, para relação gordura:álcool de $1: 7$ e concentrações de catalisador $\mathrm{KOH}$ de $0,96 \%$. Já Oliveira, et al. (2005) [14], encontraram em seu trabalho de produção de biodiesel via catálise básica a partir de óleo de soja conversões acima de 95\% para concentrações de catalisador $\mathrm{NaOH}$ de 0,5\% e relação óleo:álcool de 1:9.

Figura 2 - Superfície de resposta para a concentração de éster no biodiesel em função da relação gordura/álcool e da concentração de catalisador

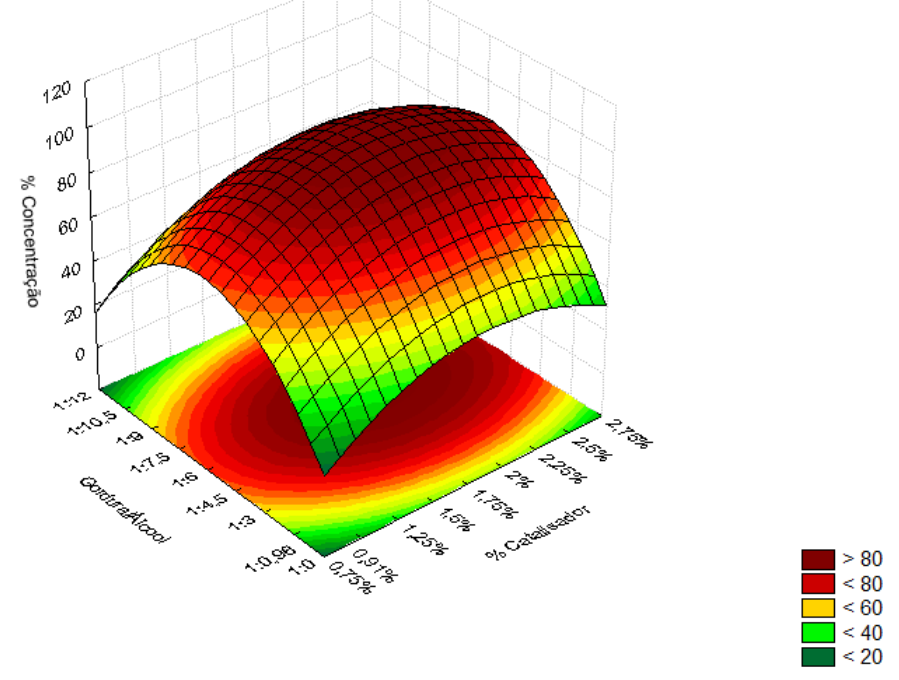

A Figura 3 refere-se à interação da temperatura e da razão gordura:etanol, onde podemos observar que a conversão em éster de biodiesel foi acima de 96,6\% para temperaturas na faixa de 45 a $70{ }^{\circ} \mathrm{C}$ e razões de gordura:etanol de 1:5 a 1:7.

Figura 3 - Superfície de Resposta para a concentração de éster no biodiesel em função da relação gordura/álcool e temperatura da reação
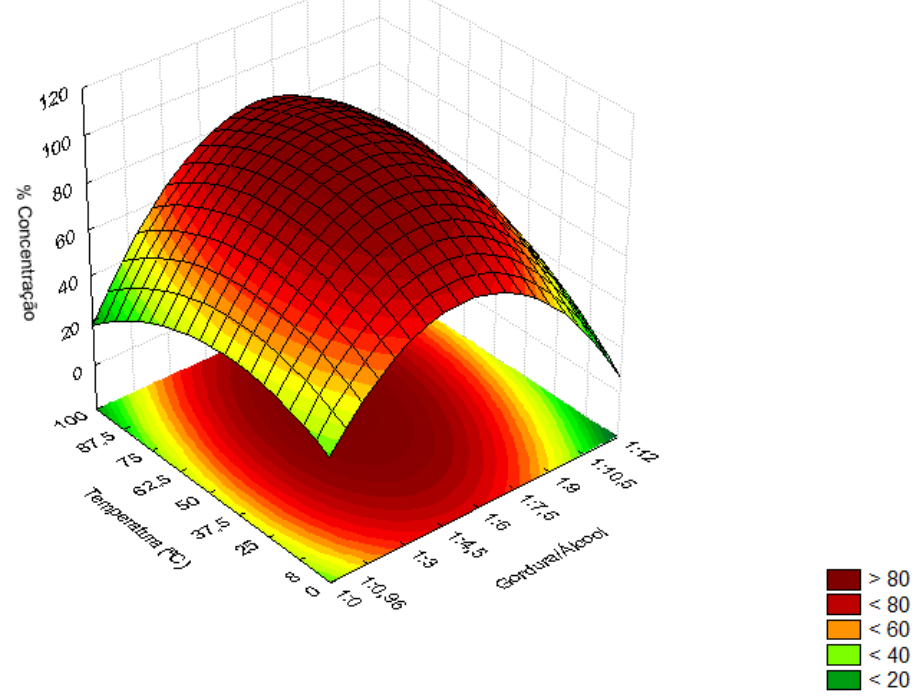
Alptekin e Canakci (2011) [10] em seu trabalho de produção de biodiesel a partir de gordura de frango utilizando álcool metílico obtiveram conversões na faixa de $80 \%$ para razão de álcool/gordura de 1:6 e temperatura de $60^{\circ} \mathrm{C}$. Estas conversões são menores que as encontradas neste trabalho para as mesmas faixas de trabalho.

Com os dados obtidos nos experimentos realizados foi possível obter uma otimização para a reação de produção de biodiesel a partir de gordura de frangos para as variáveis: temperatura (40 a $\left.60{ }^{\circ} \mathrm{C}\right)$, razão gordura/álcool (1:5 a 1:7) e as baixas concentrações de catalisador $(1,9$ a $2,10 \%)$.

O biodiesel obtido a partir das condições otimizadas de operação que foram temperatura de $50{ }^{\circ} \mathrm{C}$, concentração de catalisador de $1,75 \%$ de $\mathrm{NaOH}$ e uma razão gordura/álcool de 1:6, foi avaliado quanto a sua massa específica, viscosidade cinemática e o ponto de entupimento de filtro a frio CFPP. Os resultados encontrados serão apresentados na Tabela 3.

Tabela 3 - Propriedades do biodiesel produzido com gordura abdominal de frangos

\begin{tabular}{ccc}
\hline Propriedades & Unidades & Resultados Experimentais \\
\hline Massa Especifica a $20^{\circ} \mathrm{C}$ & $\mathrm{kg} / \mathrm{m}^{3}$ & 867 \\
Viscosidade a $40^{\circ} \mathrm{C}$ & $\mathrm{mm}^{2} / \mathrm{s}$ & 3,91 \\
CFPP & ${ }^{\circ} \mathrm{C}$ & $-2,0$ \\
\hline
\end{tabular}

As amostras de biodiesel, obtidas através dos parâmetros otimizados, foram analisadas e verificou-se que as mesmas apresentaram qualidade adequada. Os resultados da caracterização físico-química da gordura de frango demonstram que essa matéria-prima apresenta potencial para a obtenção de biodiesel, sem a utilização de etapas de preparação. Todas as características avaliadas do biodiesel atendem aos valores estabelecidos na legislação vigente e sugeridas pela Agência Nacional de Petróleo (ANP).

\section{CONCLUSÕES}

O estudo mostrou que a produção de biodiesel a partir da gordura abdominal de frango é um processo viável e uma alternativa para o agronegócio eliminar toda ou parte gordura de frango em seus efluentes, e uma oportunidade para reduzir o custo do tratamento, e também aumentar a gordura de frango com valor agregado. A partir dos dados apresentados, é possível concluir que a transesterificação alcalina de gordura abdominal de frango com etanol produz um biodiesel com alta qualidade e também com uma boa taxa de conversão.

\section{REFERÊNCIAS}

[1] Lima PCR. O biodiesel e a inclusão social - Estudo sobre recursos minerais, hídricos e energéticos (Consultoria Legislativa). Brasília: Câmara dos Deputados, Governo do Brasil; 2004. 
[2] CÂMARA, G. M. S. Biodiesel Brasil - Estado Atual da Arte. Piracicaba: ESALQ. p. $105-121,2006$.

[3]CESAR, A. S., BATALHA, M.O. Biodiesel production from castor oil in Brazil: A difficult reality. Energ. Policy, v. 38, n. 8, p.4031-4039, 2010.

[4] CENTENARO, G. S.; FURLAN, V. J.; SOUZA-SOARES, L. A. de. Gordura de frango: alternativas tecnológicas e nutricionais. Seminário: Ciências Agrárias, Londrina, v. 29, n.3, p. 619-630, jul./set. 2008.

[5] L.A. Nelson, T.A. Foglia, W.N Marmer, Lipase-catalyzed production of biodiesel, J Am. Oil Chem. Soc. 73, 8 (1996) 1191-5.

[6] G. Santori, G.D. Nicola, M. Moglie, F. Polonara, A review analyzing the industrial biodiesel production practice starting from vegetable oil refining, Applied Energy, 92 (2012) 109-132.

[7] EN 14111, Fat and Oil Derivatives - Fatty Acid Methyl Esters (FAME) - Determination of Acid Value, European Committee for Standardization, 2003.

[8] http://www.biodiesel.gov.br/legislação.html, accessed in October, 10, 2013.

[9] E.F.S.M. Ramalho; J.R. Carvalho; A.R. Albuquerque; S.F de Oliveira; E.H.S Cavalcanti; L. Stragevitch; I.M.G. santos; A.G. Souza, Low temperature behavior of poutry fat biodiesel:diesel blends, Fuel 93 (2012) 601-605.

[10] E. Alptekin, M. Canakci, Optimization of transesterification for methyl ester production from chicken fat, Fuel 90 (2011) 2630-2638.

[11] M.E. Cunha, L.C. Krause, M.S.A. Moraes, C.S. Faccini, R.A. Jacques, S.R. Almeida, M.R.A. Rodrigues, E.B. Caramão, Beef tallow biodiesel produced in a pilot scale, Fuel Processing Tecnology, 90 (2009) 570-575

[12] H.N. Bhatti, M.A. Hanif, M. Qasim, A. Rehman, Biodiesel production from waste tallow, Fuel, 87 (2008) 2961-2966.

[13] A. Cunha Jr.; V. Feddern; M. C de Pra; M. M Higarashi; P. G. de. Abreu; A. Coldebella. Synthesis and characterization of ethylic biodiesel from animal fat wastes. Fuel, [S.1.], 2012.

[14] D. Oliveira; M. Di Luccio; C. Faccio; C. D. Rosa; J. P. Bender; N. Lipke; C. Amroginski; C. Dariva ; J. V. Oliveira. Optimization of alkaline transesterification of soybean oil and castor oil for biodiesel production. Applied Biochemistry and Biotechnology, v. 121-124, p. 553-559, 2005. 